\title{
INTRODUCCIÓN \\ LA CATEGORÍA ANALÍTICA DE GÉNERO Y LA INVESTIGACIÓN FILOLÓGICA
}

\author{
José Manuel Estévez Saá \\ Dolores Ramírez Almazán \\ Leonarda Trapassi
}

Este volumen recopila algunas de las contribuciones surgidas de diferentes debates e intercambios científicos entre investigadoras e investigadores de las universidades de Sevilla, Santiago de Compostela, A Coruña, Cardiff y Roma, planteados en los últimos años por el Grupo de Investigación "Escritoras y Escrituras" de la Universidad de Sevilla (HUM 753; Junta de Andalucía).

Se trata, principalmente, de estudios de literatura y cultura, y de enfoques teóricos relacionados con la perspectiva de género. El nexo entre la Filología en el sentido tradicional, y el complejo de disciplinas y planteamientos que integran y constituyen los Estudios de Género se entiende aquí de una forma abierta y necesariamente transversal a los diferentes campos del saber. En este ámbito interdisciplinario se sitúan los debates académicos de las últimas décadas, los cursos de doctorado, de especialización y postgrado, sobre todo en Europa y Norteamérica, en torno a los Gender Studies. Éstos, nacidos en los años 80 y 90 de la redefinición de los Women's Studies, traen consigo un desplazamiento de perspectiva hacia una esfera más amplia, orientada al estudio de la construcción social y cultural de las diferencias de gender (en la dicotomía gender versus sex). La definición, préstamo de la terminología léxico-gramatical, se refiere a una categoría analítica que permite evitar los riesgos del esencialismo feminista y se convierte en la denominación de una línea de estudios comparados. Ambas vertientes, Women's y Gender Studies, están caracterizadas por una naturaleza fuertemente heterogénea y dinámica que no deja espacio a sistemas, esquemas o criterios preconcebidos. En la llamada "era postfeminista" del mundo occidental, los Estudios de Mujeres y de Género en el ámbito académico ya no se configuran como espacios vinculados sólo a un movimiento políticamente organizado de las mujeres, sino como fruto de la investigación teórica y de la revisión de conceptos y cuestiones filosóficas fundamentales. La postmodernidad ofrece, así, un nuevo prisma desde el que reflexionar en torno a temas como la identidad, el cuerpo, el espacio, la subjetividad, o la diversidad.

El interés suscitado por los Estudios de Mujeres y los Estudios de Género en todos los ámbitos del saber y en los distintos niveles académicos es también palpable en la Universidad de Sevilla y, en concreto, en nuestra Facultad de Filología, tal como lo demuestra el hecho de que en ella se inscriban, desde hace ya tiempo, proyectos, seminarios, encuentros, grupos de investigación y publicaciones, como este nuevo monográfico de Philologia Hispalensis. 
El presente volumen contiene dos secciones de ámbitos diferenciados. La primera de ellas recoge estudios de crítica literaria, análisis textual y literatura comparada. Así, el primer ensayo, de Begoña Lasa Álvarez, analiza la construcción del mito literario de Inés de Castro en la narrativa europea desde el final del siglo XVII hasta principios del siglo XIX. Marina Filgueira Figueira estudia el personaje de Madame Merle en The portrait of a Lady de Henry James. El discurso de autoafirmación femenina es el objeto de análisis del tercer artículo de esta sección, de María del Mar Rivas. Manuela Palacios González y Carmen García Navarro tratan, respectivamente, poetas irlandesas y dramaturgas británicas contemporáneas innovadoras, mientras que la relación entre la realidad social femenina en el espacio rural y la literatura es la clave utilizada por José Manuel Estévez Saá en el análisis de textos literarios y sociológicos.

En la segunda sección se reúnen ensayos sobre temas relacionados con el pasado y el presente de las teorías feministas y de género. Chris Weedon ofrece, en clave de género, un cuadro sobre cuestiones actuales de etnocentrismo y racismo en la cultura europea. Por otro lado, María Jesús Lorenzo Modia estudia el contexto proto-feminista que precede la obra de Mary Wollstonecraft. A través del proyecto de un museo de las mujeres del Mediterráneo, Genoveffa Palumbo expone algunas cuestiones relacionadas con las teorías de género y la historia de las mujeres de diferentes culturas y religiones del área mediterránea. María Jesús Cabarcos Traseira extiende la perspectiva en un sentido intercultural hacia la imagen literaria de las mujeres afrikáner en la Sudáfrica post-apartheid. Cuestiones de crítica literaria y teorías de género se exponen en los artículos de Mercedes Arriaga Flórez (las teorías de Bajtín aplicadas al estudio de literatura escrita por mujeres) y de Margarita Estévez Saá (un balance sobre la obra de Hélène Cixous). Por último, Dolores Ramírez Almazán y Leonarda Trapassi reflexionan sobre el uso de la red como medio de comunicación, diálogo e investigación sobre cuestiones de género en Italia; y Carmen Ramírez Gómez presenta un catálogo comentado de fuentes y recursos para los Estudios de Mujeres y de Género en Francia.

En definitiva, las posibilidades de investigación que la óptica de género abre a la Filología están estrictamente relacionadas con ámbitos de gran relevancia para el estudio de la literatura, la cultura y la lengua, como la construcción del canon cultural y literario, el análisis del discurso, la teoría de los géneros literarios, el análisis de temas y motivos literarios, la interrelación entre poder, literatura y lenguaje, o el sistema de transmisión de la cultura. La necesaria dimensión transnacional y transdisciplinaria de los enfoques, y la continua evolución de las tendencias críticas permiten, además, el encuentro con el "otro" a través del nexo similitud versus diferencia, que ahora, más que nunca, se reconoce de gran importancia en el proceso de comprensión de la realidad. 